\title{
Trends in the incidence and outcomes of heart failure in Ontario, Canada: 1997 to 2007
}

\author{
Darwin F. Yeung MD, Nicole K. Boom MSc, Helen Guo MSc, Douglas S. Lee MD PhD, \\ Susan E. Schultz MA MSc, Jack V. Tu MD PhD
}

\begin{abstract}
- Abstract
Background: Heart failure is a leading cause of admission to hospital, but whether the incidence of heart failure is increasing or decreasing is uncertain. We examined temporal trends in the incidence and outcomes of heart failure in Ontario, Canada.

Methods: Using population-based administrative databases of hospital discharge abstracts and physician health insurance claims, we identified 419551 incident cases of heart failure in Ontario between Apr. 1, 1997, and Mar. 31, 2008. All patients were classified as either inpatients or outpatients based on the patient's location at the time of the initial diagnosis. We tracked subsequent outcomes through linked administrative databases.
\end{abstract}

$\mathrm{H}$ eart failure is a leading cause of admission to hospital and is associated with a poor long-term prognosis. In 1996, it was projected that the number of incident hospital admissions for heart failure in Canada would more than double by 2025 because of the aging population and increasing numbers of myocardial infarction survivors. ${ }^{1}$ By 2000 , patients with heart failure accounted for the second highest number of hospital days in Canada, and the estimated 1-year case-fatality rate, after the first hospital admission, exceeded $35 \%{ }^{2,3}$ However, some recent studies suggest that admission and mortality rates for heart failure may actually be falling. It is unclear whether these changes represent lower rates of new incident cases, fewer readmissions, a shift to more outpatient care or improved survival. ${ }^{4,5}$

We sought to examine temporal trends in the incidence and outcomes of heart failure in Ontario, Canada, in both inpatient and outpatient settings to assess the progress made in reducing the population burden of heart failure and to gain insight into the effectiveness of current preventive and therapeutic strategies.
Results: The age- and sex-standardized incidence of heart failure decreased $32.7 \%$ from 454.7 per 100000 people in 1997 to 306.1 per 100000 people in 2007 ( $p<0.001)$. A comparable decrease in incidence occurred in both inpatient and outpatient settings. The greatest relative decrease occurred in patients aged 85 and over. Over the study period, 1-year risk-adjusted mortality decreased from $17.7 \%$ in 1997 to $16.2 \%$ in 2007 ( $p=0.02$ ) for outpatients, with a nonsignificant decrease from $35.7 \%$ in 1997 to $33.8 \%$ in 2007 ( $p=0.1$ ) for inpatients.

Interpretation: The incidence of heart failure decreased substantially during the study period. Nevertheless, the prognosis for patients with heart failure remains poor and is associated with high mortality.
Competing interests: None declared.

This article has been peer reviewed.

Correspondence to: Jack V.Tu, tu@ices.on.ca

CMAJ 2012. DOI:10.1503 /cmaj.111958

\section{Methods}

\section{Study setting}

We conducted a population-based study of patients in Ontario who received a diagnosis of heart failure for the first time between Apr. 1, 1997, and Mar. 31, 2008. Ontario accounts for $39 \%$ of the Canadian population. ${ }^{6}$ Its publicly funded Ontario Health Insurance Plan (OHIP) covers most physician and hospital services for all Ontario residents with no associated copayments.

This study was approved by the ethics review board of Sunnybrook Health Sciences Centre.

\section{Identification of patients}

Data were obtained from the linkage of 2 administrative databases: the Canadian Institute for Health Information's (CIHI) Discharge Abstract Database for hospital admission data (i.e., inpatient data) and the OHIP physicians claims database for ambulatory data (i.e., outpatient data). We identified heart failure events from the CIHI database using diagnosis codes 428 and $\mathbf{5} 0$ from the International Classification of Diseases (ICD), Ninth Revision Clinical Modification 
(CM) and Tenth Revision, respectively. Canada transitioned from ICD-9-CM to ICD-10 coding in 2002. ICD-9-CM and ICD-10 are comparable in classifying heart failure with a high degree of accuracy based on the Framingham criteria. ${ }^{7.8}$

From the OHIP database, we identified cases of heart failure using ICD- 8 code 428 . We considered a heart failure event to have occurred if there was either 1 documented admission for heart failure alone or 1 outpatient claim for heart failure that was followed by at least 1 additional outpatient heart failure claim within 1 year (i.e., the 2-claim method). We based our 2-claim ambulatory case identification method on a previously validated algorithm shown to have $84.8 \%$ sensitivity and $97.0 \%$ specificity in identifying heart failure events in the community from administrative databases (unpublished data, available on request). As a sensitivity analysis, we also conducted an analysis of a 1-claim identification method, in which 1 outpatient claim for heart failure was considered sufficient for identifying a case of heart failure. The date of hospital admission or the date of the first outpatient visit represents the date of diagnosis. We classified a case as an admission rather than an outpatient visit if both occurred on the same date. Outpatient cases include patients first identified and sent home from the emergency department.

Between Apr. 1, 1997, and Mar. 31, 2008, we identified 5175179 heart failure events. We excluded an event if the patient had a previous record of heart failure within 5 years before the index event. We also excluded an event if it did not represent the first instance of heart failure for a patient during the study period. We also excluded patients who were not residents of Ontario, less than 20 years old or greater than 105 years old, missing a discharge date, or reported to have a diagnosis date after a documented date of death. The remaining events constituted our cohort of incident heart failure cases.

For the subgroup analysis, we divided the cohort into 2 mutually exclusive inpatient or outpatient groups, according to where heart failure was diagnosed and care was received.

\section{Patient characteristics}

We quantified comorbid disease status using the Charlson-Deyo Comorbidity Index. ${ }^{9-12}$ A comorbid condition is coded in the secondary diagnosis field on the index discharge abstract or in the primary or secondary diagnosis fields of the discharge abstract for inpatient hospital admissions that occurred within 5 years before the index admission. The accuracy of coding of comorbidities for patients with heart failure in the CIHI Discharge Abstract Database has been validated.?
Comorbidities among outpatients were determined by claims for these conditions that occurred within 5 years before the index outpatient visit. For both inpatient and outpatient cohorts, we also determined the prevalence of atrial fibrillation or flutter, hypertension, ischemic heart disease and valvular heart disease.

\section{Mortality and readmission}

We evaluated outcome measures including 30day and 1-year readmission rates and mortality after the first documented event of heart failure. We determined the number of deaths from any cause using Ontario's Registered Persons Database. Only patients who were first diagnosed with heart failure in hospital and survived to discharge were eligible for the readmission analysis. We calculated separate rates for readmission for any cause and readmission for which heart failure was the most responsible diagnosis. We included only nonelective readmissions.

\section{Statistical analysis}

We standardized admission rates and outpatient visit rates by age, sex or both, and calculated the rates per 100000 population for each fiscal year. These rates were calculated by direct standardization using the 1991 Ontario population aged 20 years or older as the reference population. Incident cases of heart failure were followed for up to 1 year. Readmission rates and mortality were reported as the number of events per 100 patients, standardized to the age- and sexdistributions within the heart failure cohort. We used previously developed and validated logistic regression models derived from similar administrative claims data in the United States to calculate annual risk-adjusted readmission and mortality rates. These models allowed us to compare temporal trends in outcomes over time, taking into account changes in the case-mix of patients with heart failure as measured using comorbidities in the administrative databases. The mortality model included 23 candidate predictors of mortality, and the readmission model included 36 candidate predictors of readmission for patients with heart failure. ${ }^{13,14} \mathrm{~A}$ model predictor was present if there was a claim for it in the outpatient setting or if it was coded as a main diagnosis, secondary diagnosis or preadmission comorbidity during or within 5 years before the index event. To identify statistically significant changes over time, we constructed linear regression models with the year of diagnosis as the independent variable and the crude- and riskadjusted readmission and mortality rates as the dependent variables. Only $p$ values from these models are reported. 


\section{Results}

There were 419551 incident cases of heart failure in Ontario from 1997 to 2007, of which 216190 patients required admission to hospital and 203361 patients were cared for in an outpatient setting at the time of initial diagnosis (Figure 1). Women accounted for $51 \%$ of the study population, and patients aged 65 years or older represented $80 \%$ of the overall cohort.

Compared with patients whose heart failure was diagnosed in the outpatient setting, patients admitted to hospital at the time of the initial diagnosis were older (median age 77 v. $76 \mathrm{yr}$, $p<0.001$ ) and had more comorbidities (mean Charlson-Deyo score 2.1 v. $1.0, p<0.001$ ) (Table 1). Compared with outpatients, patients in hospital had higher rates of ischemic heart disease (inpatients 50.4\%; outpatients 25.5\%, $p<$ 0.001 ), diabetes (inpatients $28.2 \%$; outpatients $13.8 \%, p<0.001$ ) and hypertension (inpatients $41.8 \%$; outpatients $23.9 \%, p<0.001$ ).

The characteristics of patients with newly diagnosed heart failure showed similar trends over time regardless of the setting in which the initial diagnosis was made. Between 1997 and 2007, the median age at diagnosis increased by 2 years among inpatients $(p<0.001)$ and by 1 year among outpatients $(p<0.001)$ (Table 2$)$. There was an increase in mean Charlson-Deyo comorbidity score from 1.9 to 2.3 among inpatients ( $p$ $<0.001)$ and from 1.0 to 1.1 among outpatients $(p<0.001)$. The prevalence of diabetes increased from $26.1 \%$ to $34.6 \%$ among inpatients $(p<$ 0.001 ) and from $12.9 \%$ to $16.4 \%$ among outpatients $(p<0.001)$. The prevalence of hypertension similarly increased, from $35.7 \%$ to $47.2 \%$ among inpatients $(p<0.001)$ and from $21.5 \%$ to $25.2 \%$ among outpatients $(p<0.001)$. In contrast, the prevalence of ischemic heart disease decreased from $54.4 \%$ to $44.0 \%$ among inpatients $(p<0.001)$ and from $26.8 \%$ to $23.7 \%$ among outpatients $(p<0.001)$.

\section{Trends in the incidence of heart failure}

The age- and sex-standardized incidence rate of heart failure decreased by $32.7 \%$ from 454.7 per 100000 people to 306.1 per 100000 people $(p<$ 0.001 ) during the study period (Table 3 ). The decline in the incidence of heart failure occurred in both inpatient and outpatient settings.

The age-standardized incidence rates among men and women were not significantly different and decreased comparably throughout the study period (Figure 2). In contrast, the sex-standardized incidence of heart failure increased with age (Figure 3). Although the sex-standardized incidence of heart failure decreased over time, the rate of decline was highest among patients aged 85 years and older.

\section{Outcomes after diagnosis of heart failure}

Between 1997 and 2007, 1-year risk-adjusted mortality decreased nonlinearly from $17.7 \%$ to $16.2 \%$ among outpatients $(p=0.02)$ and from $27.0 \%$ to $25.2 \%$ among all patients $(p=0.03)$,

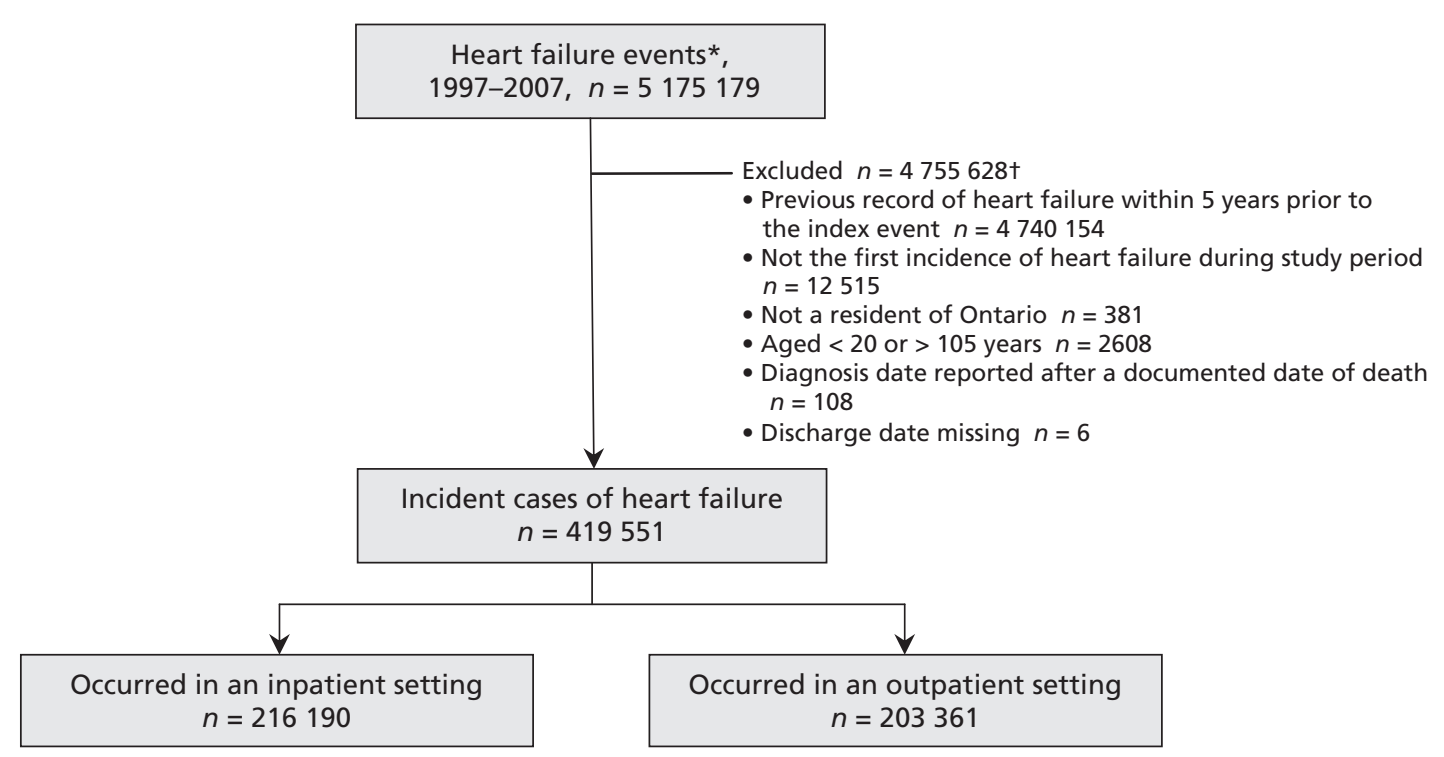

Figure 1: Flow of patients through the study, Apr. 1, 1997, to Mar. 31, 2007. *Either an admission to hospital in which heart failure is listed under any diagnostic field in the Discharge Abstract Database or an outpatient visit associated with a claim for heart failure in the Ontario Health Insurance Plan claims database followed by another heart failure claim within the same year. tSome events met multiple exclusion criteria. 
with a nonsignificant decrease of $35.7 \%$ to $33.8 \%$ among inpatients $(p=0.1)$ (Table 4$)$. Among inpatients who survived to discharge, the 1-year risk-adjusted rate of readmission for heart failure decreased from $13.4 \%$ to $10.5 \%$ ( $p=$ 0.02 ) and the 1-year risk-adjusted all-cause readmission rate decreased from $49.0 \%$ to $45.6 \%$ ( $p$ $=0.001$ ).

A sensitivity analysis of incident heart failure cases identified using a 1-outpatient-claim method as opposed to a 2-claim method showed similar declines in 1-year risk-adjusted mortality rates. The risk of incident heart failure decreased from $16.7 \%$ to $15.0 \%$ among outpatients $(p=0.004)$, from $35.2 \%$ to $33.1 \%$ among inpatients $(p=0.1)$, and from $23.1 \%$ to $20.9 \%$ among all patients $(p=$ 0.005) (Appendix 1, available at www.cmaj.ca
/lookup/suppl/doi:10.1503/cmaj.111958/-/DC1). Adopting a 1-claim method had a small impact on the number of incident cases identified in the inpatient setting, and, thus, trends in readmission rates were comparable with those found using the 2-claim method.

\section{Interpretation}

We saw a $32.7 \%$ decline in the incidence of heart failure cases in Ontario between 1997 and 2007, which translates to a $3 \%$ average annual decline; this is similar to the rates of decline previously observed in overall cardiovascular disease mortality and incidence of ischemic heart disease events in Canada. ${ }^{4}, 15$ The inclusion of outpatients is important because this group accounts for

Table 1: Characteristics of patients with incident heart failure by clinical site of diagnosis

\begin{tabular}{|c|c|c|c|}
\hline \multirow[b]{2}{*}{ Characteristic } & \multicolumn{2}{|c|}{$\%$ of patients* } & \multirow[b]{2}{*}{$p$ value } \\
\hline & $\begin{array}{l}\text { Inpatients } \\
n=216190\end{array}$ & $\begin{array}{l}\text { Outpatients } \\
n=203361\end{array}$ & \\
\hline Women & 51.2 & 50.3 & $<0.001$ \\
\hline Age, yr & & & $<0.001$ \\
\hline $20-64$ & 18.5 & 21.4 & \\
\hline $65-74$ & 23.7 & 24.3 & \\
\hline $75-84$ & 35.9 & 34.9 & \\
\hline$\geq 85$ & 21.9 & 19.4 & \\
\hline Age, yr, median & 77 & 76 & $<0.001$ \\
\hline \multicolumn{4}{|l|}{ Cardiovascular comorbidities } \\
\hline Atrial fibrillation or flutter & 25.8 & 12.1 & $<0.001$ \\
\hline Cerebrovascular disease & 13.7 & 9.1 & $<0.001$ \\
\hline Hypertension & 41.8 & 23.9 & $<0.001$ \\
\hline Ischemic heart disease & 50.4 & 25.5 & $<0.001$ \\
\hline Peripheral vascular disease & 9.4 & 4.8 & $<0.001$ \\
\hline Valvular heart disease & 10.2 & 4.3 & $<0.001$ \\
\hline \multicolumn{4}{|l|}{ Other comorbidities } \\
\hline Metastatic cancer & 4.1 & 1.8 & $<0.001$ \\
\hline Primary cancer & 9.0 & 5.5 & $<0.001$ \\
\hline Dementia & 7.1 & 3.3 & $<0.001$ \\
\hline Diabetes & 28.2 & 13.8 & $<0.001$ \\
\hline Digestive ulcer disease & 3.0 & 1.8 & $<0.001$ \\
\hline Chronic obstructive pulmonary disease & 24.2 & 11.6 & $<0.001$ \\
\hline Rheumatic disease & 2.4 & 1.5 & $<0.001$ \\
\hline Charlson-Deyo Comorbidity Index score & & & $<0.001$ \\
\hline 0 & 20.0 & 55.3 & \\
\hline 1 & 27.9 & 19.2 & \\
\hline 2 & 20.6 & 11.9 & \\
\hline$\geq 3$ & 31.5 & 13.6 & \\
\hline Charlson-Deyo score, mean & 2.1 & 1.0 & $<0.001$ \\
\hline
\end{tabular}


Table 2: Characteristics of patients with incident heart failure by clinical site and time of diagnosis

\begin{tabular}{|c|c|c|c|c|c|c|}
\hline \multirow[b]{2}{*}{ Characteristic } & \multicolumn{3}{|c|}{ Inpatients } & \multicolumn{3}{|c|}{ Outpatients } \\
\hline & $\begin{array}{c}1997 \\
n=20039\end{array}$ & $\begin{array}{c}2007 \\
n=17262\end{array}$ & $p$ value & $\begin{array}{c}1997 \\
n=19830\end{array}$ & $\begin{array}{c}2007 \\
n=17283\end{array}$ & $p$ value \\
\hline Women, \% & 51.0 & 51.8 & 0.09 & 51.8 & 47.5 & $<0.001$ \\
\hline Age, yr, \% & & & $<0.001$ & & & $<0.006$ \\
\hline $20-64$ & 17.9 & 19.0 & & 19.9 & 25.1 & \\
\hline $65-74$ & 27.0 & 20.3 & & 26.7 & 21.3 & \\
\hline $75-84$ & 35.3 & 35.3 & & 34.9 & 33.9 & \\
\hline$\geq 85$ & 19.8 & 25.4 & & 18.6 & 19.7 & \\
\hline Age, median, yr & 76 & 78 & $<0.001$ & 75 & 76 & $<0.001$ \\
\hline \multicolumn{7}{|l|}{ Cardiovascular comorbidities, \% } \\
\hline Atrial fibrillation or flutter & 22.9 & 30.2 & $<0.001$ & 10.7 & 13.9 & $<0.001$ \\
\hline Cerebrovascular disease & 15.6 & 10.7 & $<0.001$ & 10.4 & 7.0 & $<0.001$ \\
\hline Hypertension & 35.7 & 47.2 & $<0.001$ & 21.5 & 25.2 & $<0.001$ \\
\hline Ischemic heart disease & 54.4 & 44.0 & $<0.001$ & 26.8 & 23.7 & $<0.001$ \\
\hline Peripheral vascular disease & 10.6 & 7.3 & $<0.001$ & 5.3 & 4.0 & $<0.001$ \\
\hline Valvular heart disease & 9.6 & 9.5 & 0.6 & 4.2 & 4.5 & 0.1 \\
\hline \multicolumn{7}{|l|}{ Other comorbidities, \% } \\
\hline Metastatic cancer & 3.7 & 4.1 & 0.04 & 1.9 & 1.7 & 0.3 \\
\hline Primary cancer & 8.8 & 9.1 & 0.2 & 5.7 & 5.7 & 0.99 \\
\hline Dementia & 5.0 & 9.2 & $<0.001$ & 2.7 & 3.4 & $<0.001$ \\
\hline Diabetes & 26.1 & 34.6 & $<0.001$ & 12.9 & 16.4 & $<0.001$ \\
\hline Digestive ulcer disease & 3.3 & 2.7 & $<0.001$ & 2.2 & 1.5 & $<0.001$ \\
\hline Chronic obstructive pulmonary disease & 25.5 & 22.5 & $<0.001$ & 12.7 & 9.2 & $<0.001$ \\
\hline Rheumatic disease & 2.5 & 2.0 & $<0.001$ & 1.5 & 1.2 & 0.007 \\
\hline Charlson-Deyo Comorbidity Index score, \% & & & $<0.001$ & & & $<0.001$ \\
\hline 0 & 20.0 & 19.3 & & 54.5 & 56.2 & \\
\hline 1 & 30.8 & 21.2 & & 20.2 & 17.4 & \\
\hline 2 & 21.8 & 20.1 & & 12.5 & 10.9 & \\
\hline$\geq 3$ & 27.5 & 39.4 & & 12.7 & 15.5 & \\
\hline Charlson-Deyo score, mean & 1.9 & 2.3 & $<0.001$ & 1.0 & 1.1 & $<0.001$ \\
\hline
\end{tabular}

Table 3: Temporal trends in incidence of heart failure

\begin{tabular}{|c|c|c|c|c|c|c|c|}
\hline Characteristic & 1997 & 1999 & 2001 & 2003 & 2005 & 2007 & $p$ value \\
\hline Population* & 8228607 & 8456454 & 8783741 & 9111076 & 9399335 & 9678492 & \\
\hline$\geq 65 \mathrm{yr}$ & 1384739 & 1436544 & 1489294 & 1550327 & 1608698 & 1694452 & \\
\hline \multicolumn{8}{|c|}{ No. of new cases } \\
\hline All patients & 39869 & 41380 & 40795 & 36480 & 35701 & 34545 & \\
\hline Inpatients & 20039 & 21418 & 22000 & 18920 & 17906 & 17262 & \\
\hline Outpatients & 19830 & 19962 & 18795 & 17560 & 17795 & 17283 & \\
\hline \multicolumn{8}{|c|}{ Incidence ratet } \\
\hline All patients & 454.7 & 450.1 & 422.0 & 358.2 & 334.2 & 306.1 & $<0.001$ \\
\hline Inpatients & 228.3 & 232.4 & 227.0 & 185.6 & 166.4 & 151.0 & $<0.001$ \\
\hline Outpatients & 226.4 & 217.7 & 195.0 & 172.6 & 167.8 & 155.1 & $<0.001$ \\
\hline
\end{tabular}


about half of all new cases of heart failure in Ontario. Although there was a comparable and steady decline in the incidence of heart failure in both the inpatient and outpatient settings and among both men and women, the oldest age cohorts had the largest decline.

Most studies about the trends associated with heart failure have reported trends in hospital admission rates and do not include ambulatory cases. Our study included ambulatory cases, and this is one of its major strengths.

In Western Europe, Australia, New Zealand and the United States, hospital admission rates for heart failure rapidly increased before the mid-1990s, prompting concern of an impending epidemic. ${ }^{16-21}$ However, incident and total admission rates decreased steadily thereafter. ${ }^{22-28}$ Studies that examined population-based trends in the incidence of heart failure in the decades leading up to the 1990s showed weak correlation with hospital admission trends. ${ }^{29-31}$ More recently, however, reductions in admissions because of heart failure appear to reflect an actual decline in the incidence of heart failure. ${ }^{28,32}$ Our study is the largest and most recent population-based study to address this issue and provides strong evidence that the incidence of heart failure is decreasing.

The reasons for the declining incidence of heart failure are complex and cannot be definitively determined from this study. However, we hypothesize that much of the decline is driven by a decline in the incidence of ischemic heart disease events. Ischemic heart disease is the leading cause of heart failure, and thus better primary prevention (e.g., lower smoking rates, better hypertension control, better lipid status) decreases associated complications, such as heart failure. Although improved survival after myocardial infarction might lead to more patients developing heart failure, the use of interventions that preserve ejection fraction (e.g., reperfusion therapy with primary angio-

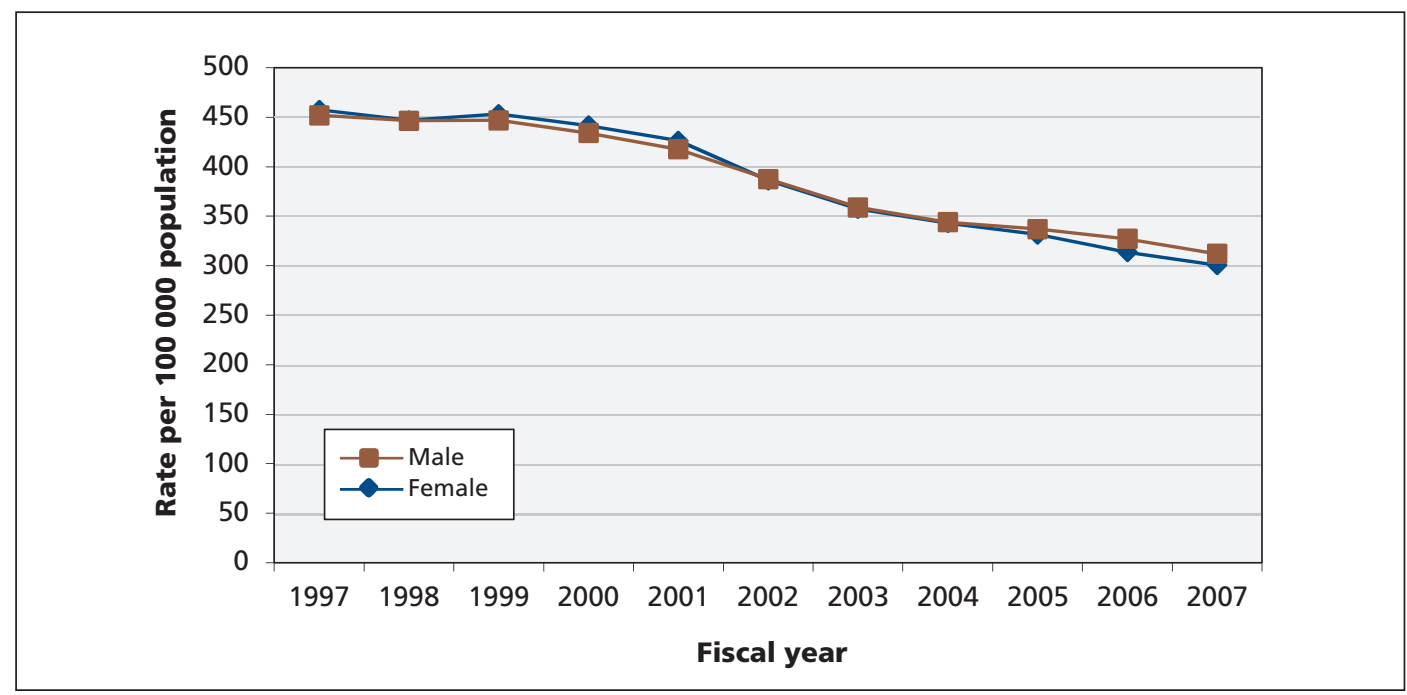

Figure 2: Age-standardized trends in incidence of heart failure, by sex.

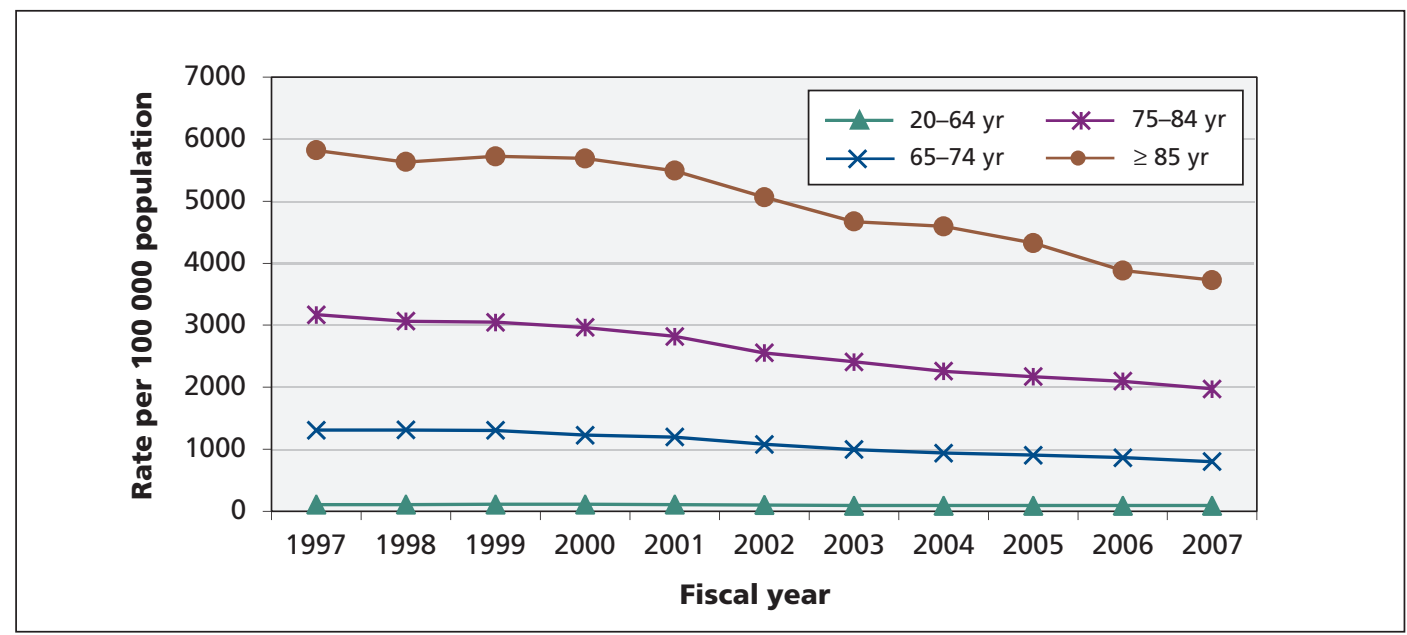

Figure 3: Sex-standardized trends in incidence of heart failure, by age group. 
plasty) has also increased, such that there may not be a net increase in heart failure cases. ${ }^{33}$ Hypertension is the second most important cause of heart failure and other studies have shown that Ontario has one of the highest rates of blood pressure control in recent years, which may also contribute to fewer patients with incident heart failure. ${ }^{34,35}$

\section{Limitations}

Our study has several limitations. First, we identified cases of heart failure in the outpatient set-

Table 4: Temporal trends in crude and risk-adjusted mortality and readmission rates, per 100 patients

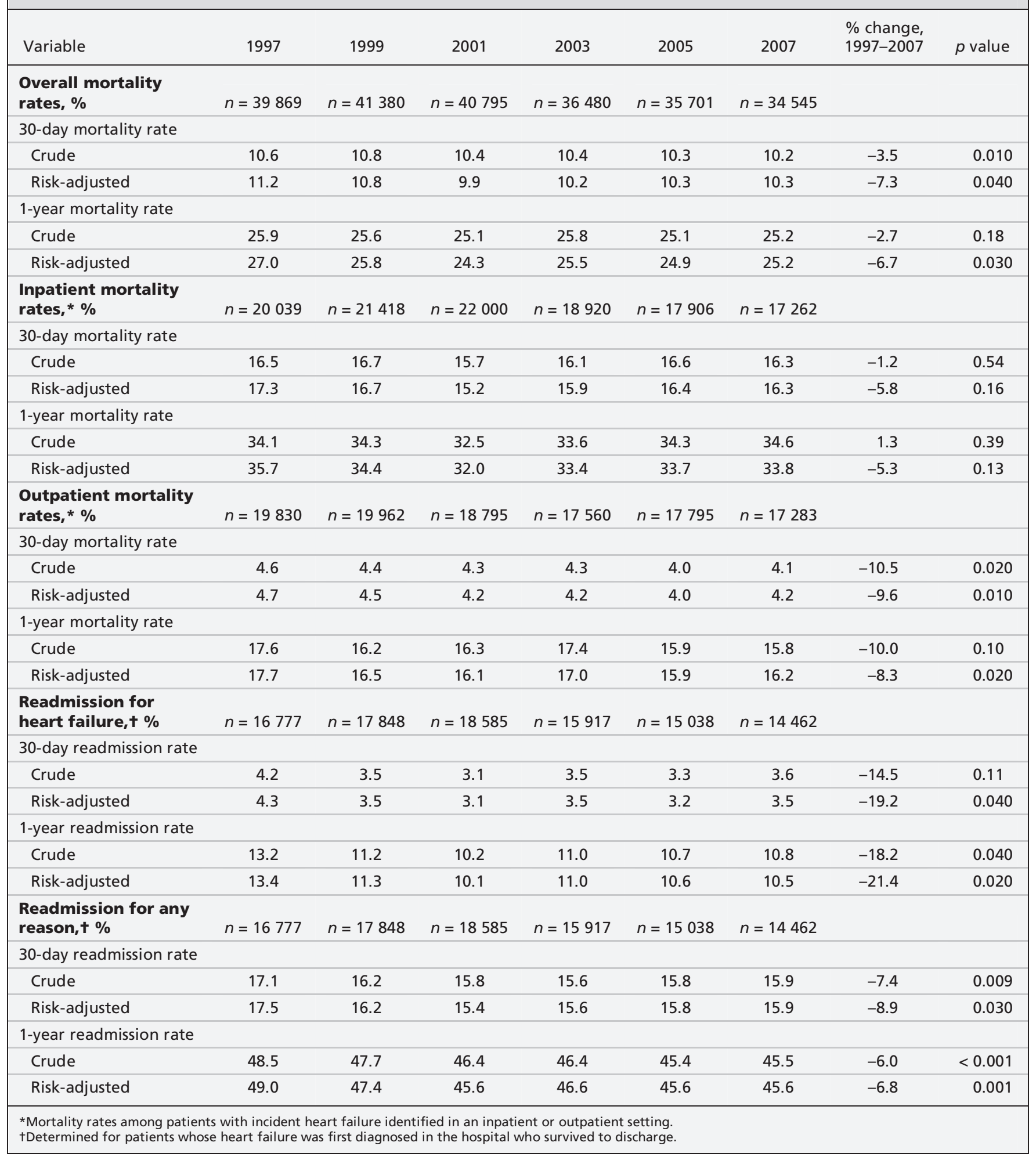


ting by requiring 2 claims for heart failure within 1 year, which may have led to us to underestimate the incidence of heart failure. A separate analysis using a 1-claim method showed higher rates of heart failure in the outpatient setting, but there was no significant difference in the overall trends (Appendix 1). We prefer the 2-claim method because it improved the specificity of our case selection. In addition, compared with hospital discharge data, outpatient claims may be less reliable in identifying comorbid conditions and may have resulted in underreporting. Nevertheless, the relative prevalence rates and trends in prevalence of comorbidities over time were comparable in the inpatient and outpatient groups.

Finally, because our databases lacked information on left ventricular ejection fraction, we could not comment on the severity of heart failure among patients and, in particular, whether patients had preserved or reduced ejection fractions, clinical features that have important implications for management and prognosis.

\section{Conclusion}

We found a substantial decrease in the incidence of heart failure in Ontario, which suggests that efforts to prevent heart failure over the past decade have been at least partially successful. The greatest decline in incidence occurred among the oldest cohorts, but it is the younger cohorts that will determine future trends in incidence. Although the results of our study are encouraging, the population continues to age and risk factors for heart failure such as diabetes and obesity are increasing, particularly in young people, which may cause the downward trend in incidence of heart failure to plateau or reverse. For patients with heart failure, the prognosis remains poor, with only modest improvement noted during our study period. Ongoing vigilance and research is required to ensure that prevention and treatments are optimized for all patients at risk of or who have heart failure.

\section{References}

1. Johansen H, Strauss B, Arnold JM, et al. On the rise: the current and projected future burden of congestive heart failure hospitalization in Canada. Can J Cardiol 2003;19:430-5.

2. Tsuyuki RT, Shibata MC, Nilsson C, et al. Contemporary burden of illness of congestive heart failure in Canada. Can J Cardiol 2003; 19:436-8.

3. Lee DS, Mamdani MM, Austin PC, et al. Trends in heart failure outcomes and pharmacotherapy: 1992 to 2000. Am J Med 2004; 116:581-9.

4. Tu JV, Nardi L, Fang J, et al. National trends in rates of death and hospital admissions related to acute myocardial infarction, heart failure and stroke, 1994-2004. CMAJ 2009;180:E118-25.

5. Campbell NR, Brant R, Johansen H, et al. Increases in antihypertensive prescriptions and reductions in cardiovascular events in Canada. Hypertension 2009;53:128-34.

6. Population by year, by province and territory. Ottawa $(\mathrm{ON})$ : Statistics Canada; 2011. Available: www.statcan.gc.ca/tables-tableaux /sum-som/101/cst01/demo02a-eng.htm (accessed 2012 Mar. 12).

7. Lee DS, Donovan L, Austin PC, et al. Comparison of coding of heart failure and comorbidities in administrative and clinical data for use in outcomes research. Med Care 2005;43:182-8.

8. Quan H, Li B, Saunders LD, et al. Assessing validity of ICD-9$\mathrm{CM}$ and ICD-10 administrative data in recording clinical conditions in a unique dually coded database. Health Serv Res 2008; 43:1424-41

9. Charlson ME, Pompei P, Ales KL, et al. A new method of classifying prognostic comorbidity in longitudinal studies: development and validation. J Chronic Dis 1987;40:373-83.

10. Deyo RA, Cherkin DC, Ciol MA. Adapting a clinical comorbidity index for use with ICD-9-CM administrative databases. $J$ Clin Epidemiol 1992;45:613-9.

11. Quan H, Sundararajan V, Halfon P, et al. Coding algorithms for defining comorbidities in ICD-9-CM and ICD-10 administrative data. Med Care 2005;43:1130-9.

12. Sundararajan V, Henderson T, Perry C, et al. New ICD-10 version of the Charlson comorbidity index predicted in-hospital mortality. J Clin Epidemiol 2004;57:1288-94.

13. Krumholz HM, Wang Y, Mattera JA, et al. An administrative claims model suitable for profiling hospital performance based on 30-day mortality rates among patients with heart failure. Circulation 2006;113:1693-701.

14. Keenan PS, Normand SL, Lin Z, et al. An administrative claims measure suitable for profiling hospital performance on the basis of 30-day all-cause readmission rates among patients with heart failure. Circ Cardiovasc Qual Outcomes 2008;1:29-37.

15. Ko DT, Newman AM, Alter DA, et al. Secular trends in acute coronary syndrome hospitalization from 1994 to 2005. Can J Cardiol 2010;26:129-34

16. McMurray J, McDonagh T, Morrison CE, et al. Trends in hospitalisation for heart failure in Scotland 1980-1990. Eur Heart $J$ 1993;14:1158-62.

17. Rodríguez-Artalejo F, Guallar-Castillon P, Banegas Banegas JR, et al. Trends in hospitalisation and mortality for heart failure in Spain 1980-1993. Eur Heart J 1997;18:1771-9.

18. Doughty R, Yee T, Sharp N, et al. Hospital admissions and deaths due to congestive heart failure in New Zealand 19881991. N Z Med J 1995; 108:473-5.

19. Reitsma JB, Mosterd A, de Craen AJM, et al. Increase for hospital admission rates for heart failure in the Netherlands 19801993. Heart 1996;76:388-92.

20. Haldeman GA, Croft JB, Giles WH, et al. Hospitalization of patients with heart failure: national discharge survey 1985-1995. Am Heart J 1999; 137:352-60.

21. Najafi F, Jamrozik K, Dobson AJ. Understanding the "epidemic of heart failure": a systematic review of trends in determinants of heart failure. Eur J Heart Fail 2009;11:472-9.

22. Jhund PS, Macintyre K, Simpson CR, et al. Long-term trends in first hospitalization for heart failure and subsequent survival between 1986 and 2003: a population study of 5.1 million people. Circulation 2009;119:515-23.

23. Schaufelberger M, Swedberg K, Koster M, et al. Decreasing one-year mortality and hospitalization rates for heart failure in Sweden; data from the Swedish Hospital Discharge Registry 1988 to 2000. Eur Heart J 2004;25:300-7.

24. Teng TH, Hung J, Knuiman M, et al. Trends in long-term cardiovascular mortality and morbidity in men and women with heart failure of ischemic versus non-ischemic aetiology in Western Australia between 1990 and 2005. Int J Cardiol 2012;158:405-10.

25. Wasywich CA, Gamble GD, Whalley GA, et al. Understanding changing patterns of survival and hospitalization for heart failure over two decades in New Zealand: utility of "days alive and out of hospital" from epidemiological data. Eur J Heart Fail 2010;12:462-8.

26. Blackledge HM, Tomlinson J, Squire IB. Prognosis for patients newly admitted to hospital with heart failure: survival trends in 12220 index admissions in Leicestershire 1993-2001. Heart 2003;89:615-20.

27. Chen J, Normand SL, Wang Y, et al. National and regional trends in heart failure hospitalization and mortality rates for Medicare beneficiaries, 1998-2008. JAMA 2011;306:1669-78.

28. Ezekowitz JA, Kaul P, Bakal JA, et al. Trends in heart failure care: Has the incident diagnosis of heart failure shifted from the hospital to the emergency department and outpatient clinics? Eur J Heart Fail 2011;13:142-7.

29. Barker WH, Mullooly JP, Getchell W. Changing incidence and survival for heart failure in a well-defined older population, 1970-1974 and 1990-1994. Circulation 2006;113:799-805.

30. Levy D, Kenchaiah S, Larson MG, et al. Long-term trends in the incidence of and survival with heart failure. N Engl J Med 2002; 347:1397-402.

31. Roger VL, Weston SA, Redfield MM, et al. Trends in heart failure incidence and survival in a community-based population. JAMA 2004;292:344-50. 
32. Curtis LH, Greiner MA, Hammill BG, et al. Early and long-term outcomes of heart failure in elderly persons, 2001-2005. Arch Intern Med 2008;168:2481-8.

33. Hassan A, Newman A, Ko DT, et al. Increasing rates of angioplasty versus bypass surgery in Canada, 1994-2005. Am Heart J 2010;160:958-65.

34. Leenen FH, Dumais J, McInnis NH, et al. Results of the Ontario survey on the prevalence and control of hypertension. CMAJ 2008; 178:1441-9.

35. Tu K, Campbell NR, Duong-Hua M, et al. Hypertension management in the elderly has improved: Ontario prescribing trends, 1994 to 2002. Hypertension 2005;45:1113-8.

Affiliations: Institute for Clinical Evaluative Sciences (Yeung, Boom, Guo, Lee, Schultz, Tu), Toronto, Ont.; the Department of Medicine (Yeung, Lee, Tu), University of Toronto, Toronto, Ont.; the Division of Cardiology (Lee), University Health Network, Toronto, Ont.; the Division of Cardiology (Tu), Schulich Heart Centre, Sunnybrook Health Sciences Centre, Toronto, Ont.

Contributors: Darwin Yeung, Douglas Lee, Susan Schulz and Jack Tu contributed to the study's concept and design. Nicole Boom and Helen Guo performed the statistical analysis. Darwin Yeung drafted the manuscript, and all of the authors critically revised it for important intellectual content.
All of the authors approved the final version of the manuscript submitted for publication.

Funding: This study was supported by a Canadian Institutes of Health Research (CIHR) Team Grants in Cardiovascular Outcomes Research and Chronic Diseases Risk and Intervention Strategies. Darwin Yeung is supported by the Comprehensive Research Experience for Medical Students program at the University of Toronto, Faculty of Medicine. Douglas Lee is supported by a Clinician-Scientist Award from CIHR. Jack Tu is supported by a Canada Research Chair in Health Services Research and Career Investigator Award from the Heart and Stroke Foundation of Ontario. The design and conduct of the study; collection, management, analysis, and interpretation of the data; and preparation, review, and approval of the manuscript were conducted completely independently of the sponsors.

Disclaimer: This study was supported by the Institute for Clinical Evaluative Sciences (ICES), which is funded by an annual grant from the Ontario Ministry of Health and LongTerm Care (MOHLTC). The opinions, results and conclusions reported in this paper are those of the authors and are independent from the funding sources. No endorsement by ICES or the Ontario MOHLTC is intended or should be inferred. 